\title{
Influence of blinding on treatment effect size estimate in randomized controlled trials of oral health interventions
}

\author{
Humam Saltaji ${ }^{1 *}$ D, Susan Armijo-Olivo², Greta G. Cummings ${ }^{3}$, Maryam Amin ${ }^{4}$ Bruno R. da Costa ${ }^{5,6}$
} and Carlos Flores-Mir ${ }^{7}$

\begin{abstract}
Background: Recent methodologic evidence suggests that lack of blinding in randomized trials can result in under- or overestimation of the treatment effect size. The objective of this study is to quantify the extent of bias associated with blinding in randomized controlled trials of oral health interventions.

Methods: We selected all oral health meta-analyses that included a minimum of five randomized controlled trials. We extracted data, in duplicate, related to nine blinding-related criteria, namely: patient blinding, assessor blinding, care-provider blinding, investigator blinding, statistician blinding, blinding of both patients and assessors, study described as "double blind", blinding of patients, assessors, and care providers concurrently, and the appropriateness of blinding. We quantified the impact of bias associated with blinding on the magnitude of effect size using a two-level meta-meta-analytic approach with a random effects model to allow for intra- and inter-metaanalysis heterogeneity.
\end{abstract}

Results: We identified 540 randomized controlled trials, included in 64 meta-analyses, analyzing data from 137,957 patients. We identified significantly larger treatment effect size estimates in trials that had inadequate patient blinding (difference in treatment effect size $=0.12 ; 95 \% \mathrm{Cl}$ : 0.00 to 0.23 ), lack of blinding of both patients and assessors (difference $=0.19 ; 95 \% \mathrm{Cl}: 0.06$ to 0.32 ), and lack of blinding of patients, assessors, and care-providers concurrently (difference $=0.14 ; 95 \% \mathrm{Cl}: 0.03$ to 0.25 ). In contrast, assessor blinding (difference $=0.06 ; 95 \% \mathrm{Cl}$ : -0.06 to 0.18 ), caregiver blinding (difference $=0.02 ; 95 \% \mathrm{Cl}$ : -0.04 to 0.09 ), principal-investigator blinding (difference $=-0.02$; $95 \% \mathrm{Cl}:-0.10$ to 0.06 ), describing a trial as "double-blind" (difference $=0.09 ; 95 \% \mathrm{Cl}$ : -0.05 to 0.22 ), and lack of an appropriate method of blinding (difference $=0.06 ; 95 \% \mathrm{Cl}$ : -0.06 to 0.18 ) were not associated with over- or underestimated treatment effect size.

Conclusions: We found significant differences in treatment effect size estimates between oral health trials based on lack of patient and assessor blinding. Treatment effect size estimates were 0.19 and 0.14 larger in trials with lack of blinding of both patients and assessors and blinding of patients, assessors, and care-providers concurrently. No significant differences were identified in other blinding criteria. Investigators of oral health systematic reviews should perform sensitivity analyses based on the adequacy of blinding in included trials.

Keywords: Randomized controlled trial, Meta-analysis, Research methodology, Study quality, Bias

\footnotetext{
* Correspondence: saltaji@ualberta.ca

'Orthodontic Graduate Program, School of Dentistry, Edmonton Clinic Health

Academy, University of Alberta, 11405-87 Ave, Edmonton, AB T6G 1C9,

Canada

Full list of author information is available at the end of the article
}

(c) The Author(s). 2018 Open Access This article is distributed under the terms of the Creative Commons Attribution 4.0 International License (http://creativecommons.org/licenses/by/4.0/), which permits unrestricted use, distribution, and reproduction in any medium, provided you give appropriate credit to the original author(s) and the source, provide a link to the Creative Commons license, and indicate if changes were made. The Creative Commons Public Domain Dedication waiver (http://creativecommons.org/publicdomain/zero/1.0/) applies to the data made available in this article, unless otherwise stated. 


\section{Background}

As evidence-based practice has grown over the past two decades, there has been a consistent generation of new randomized controlled trials (RCTs) and systematic reviews in medicine and dentistry. Currently, thousands of RCTs and meta-analyses of these trials are published every year to guide healthcare professionals in their evidence-based decisions in clinical practice. In the field of dentistry alone, nearly 50 new clinical trials and 20 systematic reviews are published every month [1-3]. These trials and systematic reviews, in turn, support much of the treatment modalities and treatment recommendations in dental practice based on the current bestidentified evidence. While RCTs, the building blocks of systematic reviews and meta-analyses, are considered to provide reliable evidence for dental decision making, RCTs are susceptible to bias (underestimation or overestimation of treatment effect size (ES) estimates) due to limitations in their design, conduct, and reporting $[4,5]$. For results and outcomes of RCTs to be generalizable and valid to specific patient subsets, they need to be properly designed, carefully conducted, and accurately reported to a standard that warrants the implementation of their results $[4,6]$.

Blinding (or "masking") has been recognized as an important criterion of high methodological quality, particularly with respect to internal validity of RCTs [7]. Blinding is broadly used in a trial to prevent performance bias (blinding of participants and care providers) and detection bias (blinding of assessors) [8-10]. Blinding can be applied at numerous levels of a trial, including participants, outcome assessors, care providers, data analysts, or other personnel. Thus, several terms (e.g., single-, double-, or triple-blind) have been used to describe blinding types $[6,11,12]$. However, the use of these terms has been inconsistent among research groups, and this contributed to conceptual and operational ambiguity. While appropriate blinding can reduce performance and detection biases, it is not always feasible to apply blinding in a trial, particularly in an RCT that involves surgical or device interventions such as oral surgery and orthodontics, as participants are often aware of the type of intervention they are receiving. The appropriateness of blinding depends on factors such as type of outcome examined (e.g., objective vs. subjective) [10] and type of intervention applied (e.g., surgical vs. drug) among others. For example, it is more difficult to implement blinding in RCTs of surgical interventions than to implement blinding in RCTs of drug interventions in which trial investigators can use placebo medications to attain adequate blinding [13].

Published meta-epidemiological studies focused on the blinding domain have found potential associations between treatment ESs and blinding of participants [14-19], care providers $[15-17,19]$, assessors $[15,17-21]$, and "double blinding" [22, 23]. While those metaepidemiological investigations were conducted within numerous health fields, the value of their conclusions may be limited, based on numerous factors, when generalized to other healthcare fields. These factors include a failure to evaluate continuous outcomes because of a preference for assessing dichotomous outcomes [15, 21, 23], emergence of inconsistent methodological findings associated with treatment ESs [15, 17, 22], and the study being "underpowered" [24] by lacking adequate sample size, which is needed to properly quantify bias in RCTs. More notably, meta-epidemiological studies have reported that the extent of bias in the treatment ES associated with blinding varied across different medical fields as well as across different types of intervention $[17,24]$.

To date, no meta-epidemiological study has examined bias related to blinding in RCTs within any oral health subspecialties or scope of practice in dentistry. Therefore, it is unclear whether the previously mentioned conclusions hold true in the field of oral health research where blinding is sometimes difficult or not feasible, especially in oral health RCTs involving surgical or device interventions, such as orthodontic trials.

Thus, our specific research questions were: (1) Do oral health RCTs with adequate blinding of participants, outcome assessors, and health care providers yield different treatment ESs than trials with lack or unclear blinding? (2) Do specific nonmethodological meta-analysis characteristics (e.g., dental specialty, type of treatment, type of outcome [objective vs. subjective], magnitude of the treatment ES estimate, heterogeneity of meta-analysis) modify the association between blinding and treatment ES estimates? Findings generated from this work could be used to improve the conduct and reporting of oral health RCTs.

\section{Methods and analysis}

This study is part of a large meta-epidemiological study that investigates the association between methodological characteristics and treatment ES estimates in oral health RCTs. The protocol for this meta-epidemiological study was registered on PROSPERO (CRD42014014070), and published a priori [25].

\section{Literature search}

We conducted a comprehensive literature search using six electronic databases (PubMed, MEDLINE, EMBASE, ISI Web of Science, Evidence-Based Medicine ReviewsCochrane Database of Systematic Reviews, and Health STAR) from database inception to May 2014. A health sciences information specialist assisted in planning the search strategy which included a combination of index terms and keywords related to systematic reviews and 
oral health. The search strategy for each database can be found in Additional file 1: Appendix 2. We also searched the American Dental Association (ADA)-Evidencebased Dentistry database [26] and hand-searched the reference lists of potentially relevant studies identified in the main search, which focused on quality of systematic reviews in oral health. We did not restrict searches to English language nor did we limit them by other means.

\section{Inclusion and exclusion criteria}

Two independent reviewers (H.S., M.A.) with dental research and clinical backgrounds screened titles and abstracts retrieved. Abstracts deemed to meet inclusion criteria were selected, and then full text reports of these and those that lacked sufficient information in the abstract were retrieved for screening. The same assessors independently determined final eligibility of full texts; discrepancies were resolved through consensus.

We included meta-analyses if they met the following predefined eligibility criteria: the meta-analysis (1) was in the field of oral health research and examined a therapeutic intervention related to treatment, prevention, or rehabilitation of dental, oral, or craniofacial diseases [27, 28]; and (2) examined at least one continuous outcome and included a minimum of five randomized trials with quantitative data of treatment ES estimates.

We subsequently selected RCTs included in the selected meta-analyses that met the following predefined eligibility criteria: (1) the design was reported to be an RCT where findings were reported in a way that allowed for calculation of treatment ES estimates; (2) the comparison was between an intervention versus a placebo, with no treatment control, or standard care (trials with a comparison of one active intervention versus another active intervention and there was no clear direction of which intervention was superior were excluded); and (3) the trials examined a therapeutic intervention related to a dental specialty recognized by the American Dental Association (ADA) [28].

\section{Data extraction}

A panel of five reviewers from diverse health research areas (H.S., C.H., J.S., J.F., S.A-O.) carried out data extraction. To ensure consistency during data extraction, two team members (H.S.; S.A-O) conducted reviewer training; the review panel evaluated 10 randomized trials not included in the final set of trials and then discussed them to achieve consistency. A similar reviewer training process was conducted in other studies performed by the same research team [29, 30]. Data extraction was performed in duplicate, that is, two assessors independently carried out data extraction, with consensus meetings employed to resolve any disagreement. One assessor with an oral health research background (H.S.) performed complete data extraction ( $n=540,100 \%)$ while another assessor (either C.H., J.S., or J.F.) with a health sciences (non-oral health) research background acted as a second assessor. The two assessors conferred with a third assessor (S.A-O.) if agreement could not be reached, to achieve complete consensus. Only consensus data were used for statistical analyses. A structured and pilot-tested data extraction template designed in a Microsoft Office Access database was used for data extraction.

The primary outcome reported for each review was used as the primary outcome for our analysis. Alternatively, the primary outcome for the analysis was determined as the outcome associated with the meta-analysis that involved the largest number of trials (in case the review's primary outcome was binary, not clearly stated, or the quantitative analysis associated with the outcome included less than five trials). Details from each included randomized trial and meta-analysis were extracted; the following elements were extracted: means, standard deviations, sample sizes, publication year, dental specialty (e.g., dental public health, endodontics, periodontics, oral medicine and oral pathology, oral and maxillofacial surgery, prosthodontics and restorative dentistry, orthodontics and dentofacial orthopaedics, and pediatric dentistry), primary outcome assessed, type of comparison in a review, number of included trials in a review, trial design (e.g., parallel, split-mouth, crossover, and factorial), type of outcome in a trial (e.g., drug vs. nondrug or subjective vs. objective [23]), and number of centers in a trial (e.g., multicenter vs. single center). To classify the type of comparison, we used the classification of the comparison implemented in the quantitative analysis reported in the review (e.g., treatment vs. control).

To assess risk of bias associated with blinding in the selected randomized trials, we applied nine blindingbased criteria (see Table 1), namely: patient blinding (blinding of participants allocated to interventions), assessor blinding (blinding of data collectors), careprovider blinding (blinding of dental clinicians and/or therapists who provided the interventions), investigator blinding (blinding of the principal investigator), statistician blinding (blinding of the data analyst), blinding of both patients and assessors, study described as "double blind" (by trial investigators), blinding of patients, assessors, and care providers concurrently, and the appropriateness of blinding (blinding that was properly implemented within the trial's components according to the primary outcome).

We scored each item following the definitions and methods for each criterion in the quality assessment tools that were found to be valid and most commonly used in health research [7,31-38]. We established our 
Table 1 Guidelines for quality assessment of included trials [7, 31-37, 63]

\begin{tabular}{|c|c|c|c|}
\hline Items /Definitions & Yes & No & Unclear \\
\hline \multicolumn{4}{|l|}{ Performance Bias } \\
\hline $\begin{array}{l}\text { Patient blinding [39]: } \\
\text { Was knowledge of the allocated } \\
\text { intervention adequately prevented } \\
\text { during the study? } \\
\text { "Blinding of patients is a must when } \\
\text { outcomes are subjective or }\end{array}$ & $\begin{array}{l}\text { Any one of the following: } \\
\text { No blinding or incomplete } \\
\text { blinding, but the review authors } \\
\text { judge that the outcome is not } \\
\text { likely to be influenced by lack of } \\
\text { blinding (Automated outcome or }\end{array}$ & $\begin{array}{l}\text { Any one of the following: } \\
\text { No blinding or incomplete } \\
\text { blinding, and the outcome } \\
\text { is likely to be influenced by } \\
\text { lack of blinding; } \\
\text { Blinding of key study }\end{array}$ & $\begin{array}{l}\text { Any one of the following: } \\
\text { Insufficient information to } \\
\text { permit judgement of 'Low } \\
\text { risk' or 'High risk'; } \\
\text { The study did not address } \\
\text { the issue of blinding. }\end{array}$ \\
\hline
\end{tabular}

self-reported. When Outcomes are measured by an assessor, then assessors should be blinded to group allocation. When Outcomes are automated (there is no assessor involved) then, blinding of participants or assessors is not an issue."

Blinded therapist/care-provider participants and key study personnel ensured, and unlikely that the blinding could have been broken; Objectives automatized outcomes coming from databases or hospital register office.

The study describes in the title, abstract, or text that the therapists/ care-providers were blinded. The blinding was appropriate.

Blinded principal-investigator

Blinded statistician

Detection Bias

Assessor blinding [39]:

Was knowledge of the allocated intervention adequately prevented during the study?

Detection bias due to knowledge of the allocated interventions by outcome assessors.

\section{Detection/Performance Bias}

Blinding of both patients and assessors) [39]

Study described as double blind

blinding of patients, assessors, and caregivers concurrently

The method of blinding was appropriate the person doing the assessments nor method appropriately.
The study describes in the title, abstract, or text that the investigator was blinded. The blinding was appropriate.

The study describes in the title, abstract, or text that the statistician was blinded. The blinding was appropriate.

Any one of the following: No blinding of outcome assessment, No blinding of outcome but the review authors judge that the assessment, and the outcome measurement is not likely to outcome measurement is be influenced by lack of blinding; Blinding of outcome assessment ensured, and unlikely that the blinding could have been broken.

Both patient blinding and assessor blinding were judged as having low risk of bias.

"Double blind" is the description in the study related to "blindness."

Also, it should be stated that neither the study participants could identify the intervention being assessed.

Both patient blinding and assessor blinding were judged as having low risk of bias. Also, care-providers are blinded.

The authors use the blinding participants and personnel attempted, but likely that the blinding could have been broken, and the outcome is likely to be influenced by lack of blinding.

The study describes in the title, abstract, or text that the therapists/care-providers were not blinded, or because of the nature of the intervention (e.g., exercise prescription or supervision etc.), the therapist could not be blinded.

The study describes in the title, abstract, or text that the investigator was not blinded.

The study describes in the title, abstract, or text that the statistician was not blinded. likely to be influenced by lack of blinding;

Blinding of outcome assessment, but likely that the blinding could have been broken and the outcome measurement is likely to be influenced by lack of blinding.

Both patient blinding and assessor blinding were judged as having high risk of bias

Not described as double blind.

Both patient blinding and assessor blinding were judged as having high risk of bias. Also, care-providers are not blinded.

There is no blinding or incomplete blinding is performed, and the
There is insufficient information to permit a judgment.

There is insufficient information to permit a judgment.

There is insufficient information to permit a judgment.

Any one of the following: Insufficient information to permit judgement of 'Low risk' or 'High risk';

The study did not address the issue of blinding.

Both patient blinding and assessor blinding were judged as having unclear risk of bias.

There is insufficient information to permit a judgment.

Both patient blinding and assessor blinding were judged as having unclear risk of bias. Also, care-providers are judged as "unclear". 
Table 1 Guidelines for quality assessment of included trials [7, 31-37, 63] (Continued)

\begin{tabular}{|c|c|c|c|}
\hline Items /Definitions & Yes & No & Unclear \\
\hline & $\begin{array}{l}\text { Blinding of participants/patients is a } \\
\text { "must" when outcomes are subjective } \\
\text { or self-reported. } \\
\text { When outcomes are measured by } \\
\text { an assessor, the assessors should be } \\
\text { blinded to group allocation. } \\
\text { Also, score "completely done" when } \\
\text { it is unlikely that the blinding could } \\
\text { have been broken and the } \\
\text { nonblinding of others is unlikely to } \\
\text { introduce bias. No blinding, but the } \\
\text { review authors judge that the } \\
\text { outcome and the outcome } \\
\text { measurement are not likely to be } \\
\text { influenced by lack of blinding. } \\
\text { Objectives automatized outcomes } \\
\text { coming from databases or hospital } \\
\text { register office. }\end{array}$ & $\begin{array}{l}\text { outcome or outcome measurement } \\
\text { is likely to be influenced by lack of } \\
\text { blinding. }\end{array}$ & $\begin{array}{l}\text { There is insufficient } \\
\text { information to permit a } \\
\text { judgment. }\end{array}$ \\
\hline
\end{tabular}

evaluation based on the chosen primary outcome of analysis, and employed a 3-level ordinal scoring scheme comprised of "high, unclear, low" risk of bias [39] for two domains (patient blinding and assessor blinding) and "yes, no, unclear" [7] for the other five domains. See Table 1 for further details of the blinding-based criteria used in the study.

Moreover, we assessed whether each individual component of a trial (participants, assessors, care-providers, statisticians, or investigators) would be blinded to study measurements: random assignment, hypothesis, details of interventions, outcome measures, and outcome analysis.

\section{Data analysis}

To describe the blinding in the RCTs selected, we conducted descriptive analyses including proportions and percentages of study elements. To examine whether dental RCTs with adequate blinding reported different treatment ES estimates than trials with lack of blinding, we conducted a two-level analysis using a meta-metaanalytic approach with a random-effects model following guidelines established by Sterne et al. [40]. This type of analysis is reported to be the most effective to address our research question, given that the methodological approach used for our meta-epidemiological analysis takes into account heterogeneity between randomized trials, within meta-analyses in a first step, and among metaanalyses in a second step [41, 42]. We obtained raw data for each trial from each meta-analysis and cross-checked the numbers with the data reported in the primary trial.

For the "within meta-analyses level" (first level analysis), we obtained a standardized treatment ES estimate for the primary outcome of each randomized trial, as outlined by Cohen [43]. A negative treatment ES estimate entailed a favourable effect of the tested intervention. We obtained data from each selected randomized trial and meta-analysis. We considered a trial if it was included in more than one meta-analysis, only once (from the meta-analysis with the fewer number of trials). We divided included trials, for each meta-analysis and each randomized trial component, into two groups according to the relevant quality criterion (e.g., participant blinding, assessor blinding, care-provider blinding) those that adequately addressed the criterion and those that did not ("no" or "unclear"). We calculated two treatment ES estimates for each meta-analysis: the first corresponded to the pooled treatment ES estimate from trials including the characteristic of interest (e.g., patient blinding) and the second corresponded to the pooled treatment ES estimate from trials where the characteristic of interest (e.g., no or unclear patient blinding) was not met. We conducted inverse-variance random-effects meta-analysis to derive pooled treatment ES estimates for each meta-analysis, and calculated the DerSimonian and Laird estimates of variance to determine heterogeneity between randomized trials [41]. Thus, for each meta-analysis, we used meta-regression approaches to derive the difference between pooled estimates from trials with and without the characteristic of interest, as well as its standard error. A negative difference in treatment ES estimate implied that trials with the blinding-based item yielded a more favourable treatment ES estimate for the tested intervention.

For the "among meta-analyses level" (second level analysis), we pooled findings of the previous analysis (combined differences from all meta-analyses) to describe the effect of each trial's component across all meta-analyses. We combined differences in treatment ES estimates at this stage using inverse-variance random-effects meta-analysis [41] to account for between-meta analysis heterogeneity, and calculated the DerSimonian and Laird estimates of variance to determine heterogeneity between meta-analyses [41]. All $p$-values were two-sided. 
To examine whether specific characteristics modify the associations between blinding and the treatment ES estimate, we stratified the analyses with interaction tests based on $\mathrm{Z}$ scores according to the following factors: type of outcome (objective vs. subjective), dental speciality (periodontal vs. other interventions, or dental public health vs. other interventions), magnitude of the treatment ES estimate (small, if $>-0.5$ vs. large, if $\leq-0.5$ ), and heterogeneity of the meta-analysis (low if $\mathrm{t}^{2}<0.06$ vs. high if $\tau^{2} \geq 0.06$; the cut-off of $\tau^{2}=0.06$ roughly amounts to a difference between the largest and the smallest treatment ES estimate, where the smallest treatment ES estimate $=1$ ). We performed all analyses using STATA statistical software version 14 (College Station, TX: StataCorp LP). The analysis was conducted by the principal investigator who was trained, and supervised by a team member with extensive experience in analyses of meta-epidemiological studies.

We calculated the sample size according to recommendations in Hempel et al. [44] and Berkman et al. [24]. From previous meta-epidemiological investigations [30, 45, 46], we anticipated obtaining a difference in treatment ES estimates of at least $0.15 \quad(\mathrm{SE}=0.087)$ between trials with and without quality criteria [45]. This magnitude of difference in treatment ES estimates has been claimed to resemble nearly $1 / 4$ to $1 / 2$ of classic treatment ES estimates for interventions in fields similar to the field of dentistry [45]. Accordingly, we planned a sample size of nearly 500 randomized trials included in 60 systematic reviews to demonstrate such a meaningful difference. This is approximately two to three times the number of trials included in previously published metaepidemiological investigations $[18,45,47]$.

\section{Results}

\section{Characteristics of selected systematic reviews and} included randomized trials

The updated database of dental, oral, and craniofacial systematic reviews [45] included 1408 records (published between 1991 and 2014) of which 152 systematic reviews with meta-analyses were judged to be potentially relevant; of these, 64 (32 Cochrane and 32 non-Cochrane reviews) satisfied the eligibility criteria for the present report. The complete list of excluded reviews is available upon request.

Overall, the chosen meta-analyses were published between 2002 and 2014 (median year of publication: 2010; interquartile range [IQR] 2006-2012), while the median number of trials included in the meta-analyses was six (IQR 6-10). A total of 540 trials analyzing 137,957 patients were considered for this study $[48,49]$. The meta-analyses examined a therapeutic intervention related to the fields of periodontics (36 reviews; 271 trials), dental public health and pediatric dentistry (10 reviews; 145 trials), oral medicine and pathology (11 reviews; 80 trials), oral and maxillofacial surgery (4 reviews; 26 trials), orthodontics and dentofacial orthopedics (2 reviews; 12 trials), and restorative dentistry (1 review; 6 trials). Approximately one-fifth of the trials were multicenter trials, nearly one-third of the trials placebo-controlled $(n=204$; $37.8 \%)$, and two-thirds of the trials examined were nondrug $(n=359 ; 66.5 \%)$ or nonsurgical $(n=370 ; 68.5 \%)$ interventions. The majority of trials used parallel design $(n=372$; $68.9 \%)$, and one-quarter used split-mouth design $(n=126$; 23.3\%). Additional file 2: Appendix 1 provides further details on characteristics of the chosen meta-analyses.

\section{Blinding in dental randomized trials}

Blinding of patients was judged as adequate (low risk of bias $)$ in $71.5 \%(n=386)$ of the trials, and blinding of the outcome assessment was judged as adequate (low risk of bias) in 59.4\% of the trials. Blinding of both patients and assessors was judged as adequate in $72.8 \%$ of trials $(n=273)$, and $76.5 \%(n=117)$ of trials were assessed as adequate with respect to blinding of patients, assessors, and careproviders. Blinding of the assessor was reported in $59.4 \%$ of trials $(n=321)$, while blinding of patients was unclear/not reported in nearly half of trials $(n=279 ; 51.7 \%)$. Two-thirds of trials were not described as double-blind $(n=358 ; 66.3 \%)$. The method of blinding was appropriate in $53 \%$ of trials $(n$ $=286$ ), while blinding of the principal investigator and statistician was unclear/not reported in the vast majority of trials. Tables 2 and 3 provide details of the blinding of individual components (participants, assessors, principal investigators, care-providers, and statisticians), and the level of blinding (random assignment, hypothesis, details of intervention, and data analysis) in RCTs of oral health interventions.

\section{Impact of patient blinding on treatment effect size estimate}

Figure 1 displays a forest plot of the difference in treatment ES estimates between trials with the presence and lack of patient blinding. Twenty-eight meta-analyses, including 275 trials that analyzed 109,753 patients, provided information for this meta-epidemiological analysis. Results of the analysis showed that trials with inadequate patient blinding had significantly larger treatment ES estimates (difference $=0.12$, 95\% confidence interval 0.00 to $0.23, p=0.046$ ). However, the impact of patient blinding on treatment ES estimates stratified by other characteristics of meta-analyses (heterogeneity of meta-analysis, type of outcome, and dental speciality) was not statistically significant for any of the characteristics (see Fig. 2a).

\section{Impact of assessor blinding on treatment effect size estimate}

Figure 3 displays a forest plot of the difference in treatment ES estimates between trials with a presence and a lack of 
Table 2 Blinding in randomized trials of oral health interventions $(N=540)$

\begin{tabular}{|c|c|c|c|}
\hline \multirow[t]{2}{*}{ Domain } & \multicolumn{3}{|c|}{ Risk of Bias Assessment, N (\%) } \\
\hline & Low Risk & High Risk & Unclear Risk \\
\hline Blinding of patients/participants & $386(71.5)$ & $7(1.3)$ & $147(27.2)$ \\
\hline Blinding of assessors & $321(59.4)$ & $16(3.0)$ & $203(37.6)$ \\
\hline Blinding of both patients and assessors ${ }^{a}$ & $273(72.8)$ & $7(1.9)$ & $95(25.3)$ \\
\hline $\begin{array}{l}\text { Blinding of patients, assessors, and } \\
\text { care-providers concurrently }{ }^{\mathrm{b}}\end{array}$ & $117(76.5)$ & $7(4.6)$ & $29(19.0)$ \\
\hline \multirow[t]{2}{*}{ Item } & \multicolumn{3}{|c|}{ Quality Assessment, N (\%) } \\
\hline & Yes & No & Unclear/Not reported \\
\hline Study described as double-blind & $181(33.5)$ & $358(66.3)$ & $1(0.2)$ \\
\hline Blinding of assessors & $321(59.4)$ & $16(3.0)$ & $203(37.6)$ \\
\hline Blinding of patients & $192(35.6)$ & $69(12.8)$ & $279(51.7)$ \\
\hline Blinding of therapists/care-providers & $134(24.8)$ & $356(65.9)$ & $50(9.3)$ \\
\hline Blinding of principal investigator & $33(6.1)$ & $10(1.9)$ & $497(92.0)$ \\
\hline Blinding of data analyst & $9(1.7)$ & $3(0.6)$ & $528(97.8)$ \\
\hline Method of blinding appropriate & $286(53)$ & $17(3.1)$ & $237(43.9)$ \\
\hline
\end{tabular}

${ }^{a}$ Does not equal $100 \%$ for overall, as the item was not applicable in 165 trials

${ }^{b}$ Does not equal $100 \%$ for overall, as the item was not applicable in 387 trials

assessor blinding. Forty-four meta-analyses, including 408 trials that analyzed 119,282 patients, provided information for this meta-epidemiological analysis. Although assessor blinding was not associated with a statistically significant difference in treatment ES, trials with lack of assessor blinding tended to inflate treatment ES estimates when compared with trials with a presence of assessor blinding (difference $=$ $0.06,95 \%$ confidence interval -0.06 to $0.18, p=0.316$ ). The results of the stratified analyses show that none of the metaanalyses characteristics had a statistically significant interaction with the treatment ES estimate (see Fig. 2b).

\section{Impact of care-provider blinding on treatment effect size estimate}

Figure 4a displays a forest plot of the difference in treatment ES estimates between randomized trials with a presence and a lack of care-provider blinding. Eighteen meta-analyses, including 408 trials that analyzed 109,383 patients, provided information for this metaepidemiological analysis. Care-provider blinding was not associated with a statistically significant difference in treatment ES estimates (difference $=0.02,95 \%$ confidence interval -0.04 to $0.09, p=0.509$ ). The results of the stratified analyses show that none of the meta-analyses characteristics had a statistically significant interaction with the treatment ES (see Fig. 2c).

\section{Impact of principal-investigator blinding on treatment effect size estimate}

Figure $4 \mathrm{~b}$ displays a forest plot of the difference in treatment ES estimates between randomized trials with a

Table 3 Type of blinding in randomized trials of oral health interventions ( $N=540$ ); N (\%)

\begin{tabular}{|c|c|c|c|c|c|c|c|c|c|c|c|c|c|c|c|}
\hline \multirow[t]{2}{*}{ Component } & \multicolumn{3}{|c|}{ Random allocation } & \multicolumn{3}{|c|}{ Hypothesis } & \multicolumn{3}{|c|}{ Details of intervention } & \multicolumn{3}{|c|}{ Outcome assessment } & \multicolumn{3}{|c|}{ Data analysis } \\
\hline & Yes & No & $\begin{array}{l}\text { Unclear/ } \\
\text { NR }\end{array}$ & Yes & No & $\begin{array}{l}\text { Unclear/ } \\
\text { NR }\end{array}$ & Yes & No & $\begin{array}{l}\text { Unclear/ } \\
\text { NR }\end{array}$ & Yes & No & $\begin{array}{l}\text { Unclear/ } \\
\text { NR }\end{array}$ & Yes & No & $\begin{array}{l}\text { Unclear/ } \\
\text { NR }\end{array}$ \\
\hline Participants & $\begin{array}{l}194 \\
(35.93)\end{array}$ & $\begin{array}{l}70 \\
(12.96)\end{array}$ & $\begin{array}{l}276 \\
(51.11)\end{array}$ & $\begin{array}{l}1 \\
(0.19)\end{array}$ & $\begin{array}{l}12 \\
(2.22)\end{array}$ & $\begin{array}{l}527 \\
(97.59)\end{array}$ & $\begin{array}{l}2 \\
(0.37)\end{array}$ & $\begin{array}{l}221 \\
(40.93)\end{array}$ & $\begin{array}{l}17 \\
(58.70)\end{array}$ & $\begin{array}{l}0 \\
(0.0)\end{array}$ & $\begin{array}{l}71 \\
(13.15)\end{array}$ & $\begin{array}{l}469 \\
(86.85)\end{array}$ & $\begin{array}{l}0 \\
(0.0)\end{array}$ & $\begin{array}{l}0 \\
(0.0)\end{array}$ & $\begin{array}{l}540 \\
(100.0)\end{array}$ \\
\hline Assessors & $\begin{array}{l}322 \\
(59.63)\end{array}$ & $\begin{array}{l}15 \\
(2.78)\end{array}$ & $\begin{array}{l}203 \\
(37.59)\end{array}$ & $\begin{array}{l}1 \\
(0.19)\end{array}$ & $\begin{array}{l}11 \\
(2.04)\end{array}$ & $\begin{array}{l}528 \\
(97.78)\end{array}$ & $\begin{array}{l}8 \\
(1.48)\end{array}$ & $\begin{array}{l}37 \\
(6.85)\end{array}$ & $\begin{array}{l}495 \\
(91.67)\end{array}$ & NA & NA & NA & $\begin{array}{l}0 \\
(0.0)\end{array}$ & $\begin{array}{l}0 \\
(0.0)\end{array}$ & $\begin{array}{l}540 \\
(100.0)\end{array}$ \\
\hline $\begin{array}{l}\text { Principal } \\
\text { Investigator }\end{array}$ & $\begin{array}{l}32 \\
(5.93)\end{array}$ & $10(1.85)$ & $\begin{array}{l}498 \\
(92.22)\end{array}$ & $\begin{array}{l}0 \\
(0.0)\end{array}$ & $\begin{array}{l}0 \\
(0.0)\end{array}$ & $\begin{array}{l}540 \\
(100.00)\end{array}$ & $\begin{array}{l}0 \\
(0.0)\end{array}$ & $\begin{array}{l}0 \\
(0.0)\end{array}$ & $\begin{array}{l}540 \\
(100.0)\end{array}$ & $\begin{array}{l}1 \\
(0.19)\end{array}$ & $\begin{array}{l}2 \\
(0.37)\end{array}$ & $\begin{array}{l}533 \\
(99.44)\end{array}$ & $\begin{array}{l}0 \\
(0.0)\end{array}$ & $\begin{array}{l}0 \\
(0.0)\end{array}$ & $\begin{array}{l}540 \\
(100.0)\end{array}$ \\
\hline $\begin{array}{l}\text { Care- } \\
\text { providers }\end{array}$ & $\begin{array}{l}136 \\
(25.19)\end{array}$ & $\begin{array}{l}351 \\
(65.00)\end{array}$ & $\begin{array}{l}53 \\
(9.81)\end{array}$ & $\begin{array}{l}2 \\
(0.37)\end{array}$ & $\begin{array}{l}10 \\
(1.85)\end{array}$ & $\begin{array}{l}528 \\
(97.78)\end{array}$ & $\begin{array}{l}0 \\
(0.0)\end{array}$ & $\begin{array}{l}0 \\
(0.0)\end{array}$ & $\begin{array}{l}540 \\
(100.0)\end{array}$ & $\begin{array}{l}1 \\
(0.19)\end{array}$ & $\begin{array}{l}16 \\
(2.96)\end{array}$ & $\begin{array}{l}523 \\
(96.85)\end{array}$ & $\begin{array}{l}0 \\
(0.0)\end{array}$ & $\begin{array}{l}0 \\
(0.0)\end{array}$ & $\begin{array}{l}540 \\
(100.0)\end{array}$ \\
\hline Statisticians & $\begin{array}{l}9 \\
(1.67)\end{array}$ & $\begin{array}{l}3 \\
(0.56)\end{array}$ & $\begin{array}{l}528 \\
(97.78)\end{array}$ & $\begin{array}{l}1 \\
(0.19)\end{array}$ & $\begin{array}{l}0 \\
(0.0)\end{array}$ & $\begin{array}{l}539 \\
(99.81)\end{array}$ & $\begin{array}{l}0 \\
(0.0)\end{array}$ & $\begin{array}{l}0 \\
(0.0)\end{array}$ & $\begin{array}{l}540 \\
(100.0)\end{array}$ & $\begin{array}{l}0 \\
(0.0)\end{array}$ & $\begin{array}{l}0 \\
(0.0)\end{array}$ & $\begin{array}{l}540 \\
(100.0)\end{array}$ & NA & NA & NA \\
\hline
\end{tabular}

NA not applicable, NR not reported 


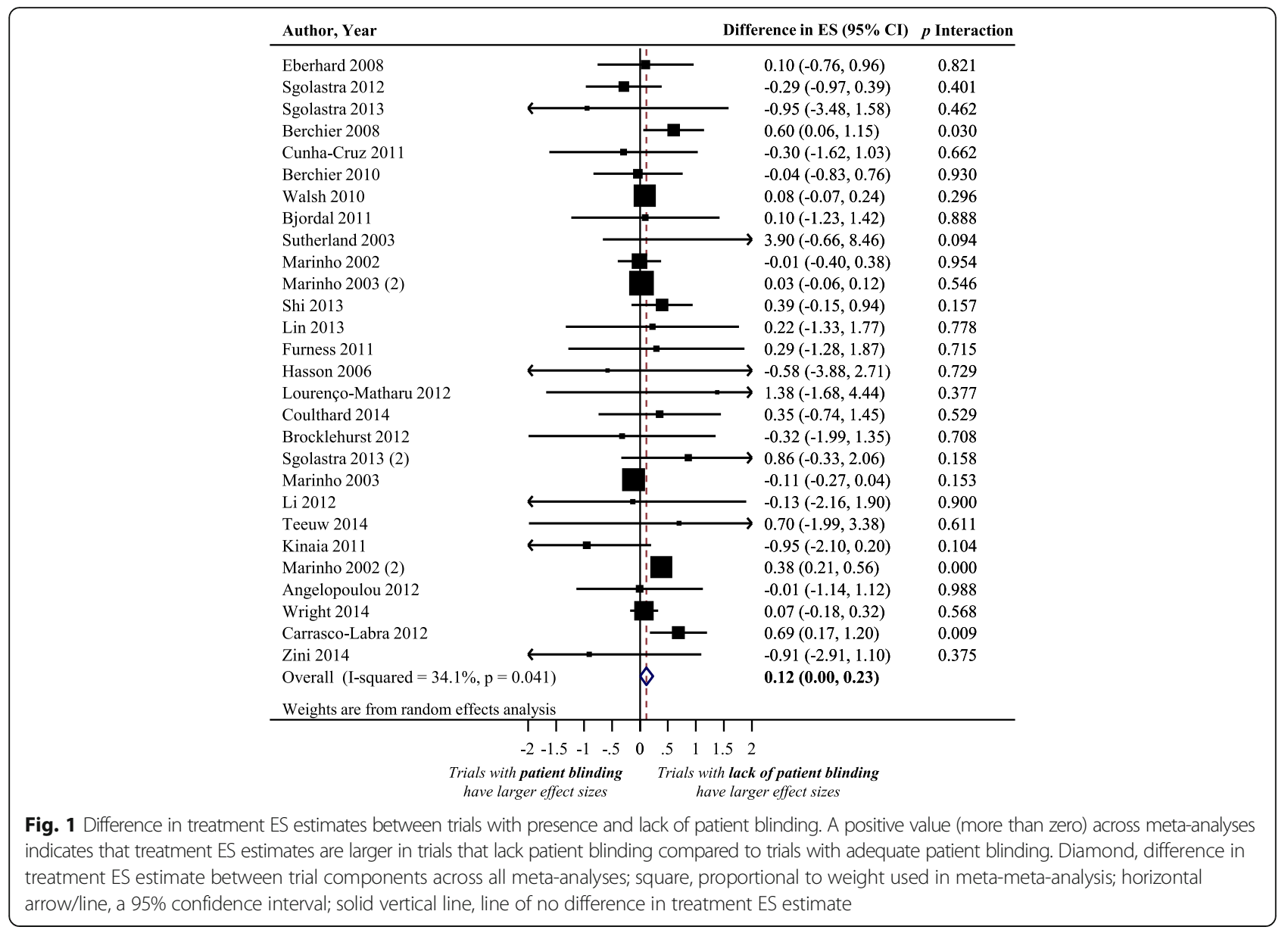

presence and a lack of principal-investigator blinding. Eighteen meta-analyses, including 162 trials that analyzed 59,757 patients, provided information for this meta-epidemiological analysis. Principal-investigator blinding was not associated with a statistically significant difference in treatment ES estimates (difference $=-0.02$, $95 \%$ confidence interval -0.10 to $0.06, p=0.641$ ). Results of stratified analyses show that none of the metaanalyses characteristics had a statistically significant interaction with the treatment ES (see Fig. 2d).

\section{Impact of data-analyst blinding on treatment effect size estimate}

Due to the small number of trials with adequate blinding of the data-analyst, meta-epidemiological analysis of the data could not be performed for this criterion.

\section{Impact of describing a trial as "double-blind" on treatment effect size estimate}

Figure 5 displays a forest plot of the difference in treatment ESs between randomized trials with and without reporting "double blinding." Twenty-eight meta-analyses, including 294 trials that analyzed 111,052 patients, provided information for this meta-epidemiological analysis. Trials not described as double-blind tended to exaggerate treatment ES estimate compared to trials described as double-blind. However, differences were not statistically significant (difference $=0.09,95 \%$ confidence interval -0 . 05 to $0.22, p=0.203$ ). The results of stratified analyses showed that none of the meta-analyses characteristics had a statistically significant interaction with the treatment ES (see Fig. 6a).

\section{Impact of blinding of both patients and assessors on treatment effect size estimate}

Figure 7a shows a forest plot of the difference in treatment ES estimate in randomized trials with and without blinding of both patients and assessors. Nineteen metaanalyses, including 224 trials that analyzed 106,716 patients, provided information for this metaepidemiological analysis. Meta-epidemiological results showed a statistically significant difference between the treatment ES estimate in RCTs that implemented patient and assessor blinding concurrently (difference $=0.19$, $95 \%$ confidence interval 0.06 to $0.32, p=0.004$ ) and the treatment ES estimate in randomized trials that did not 


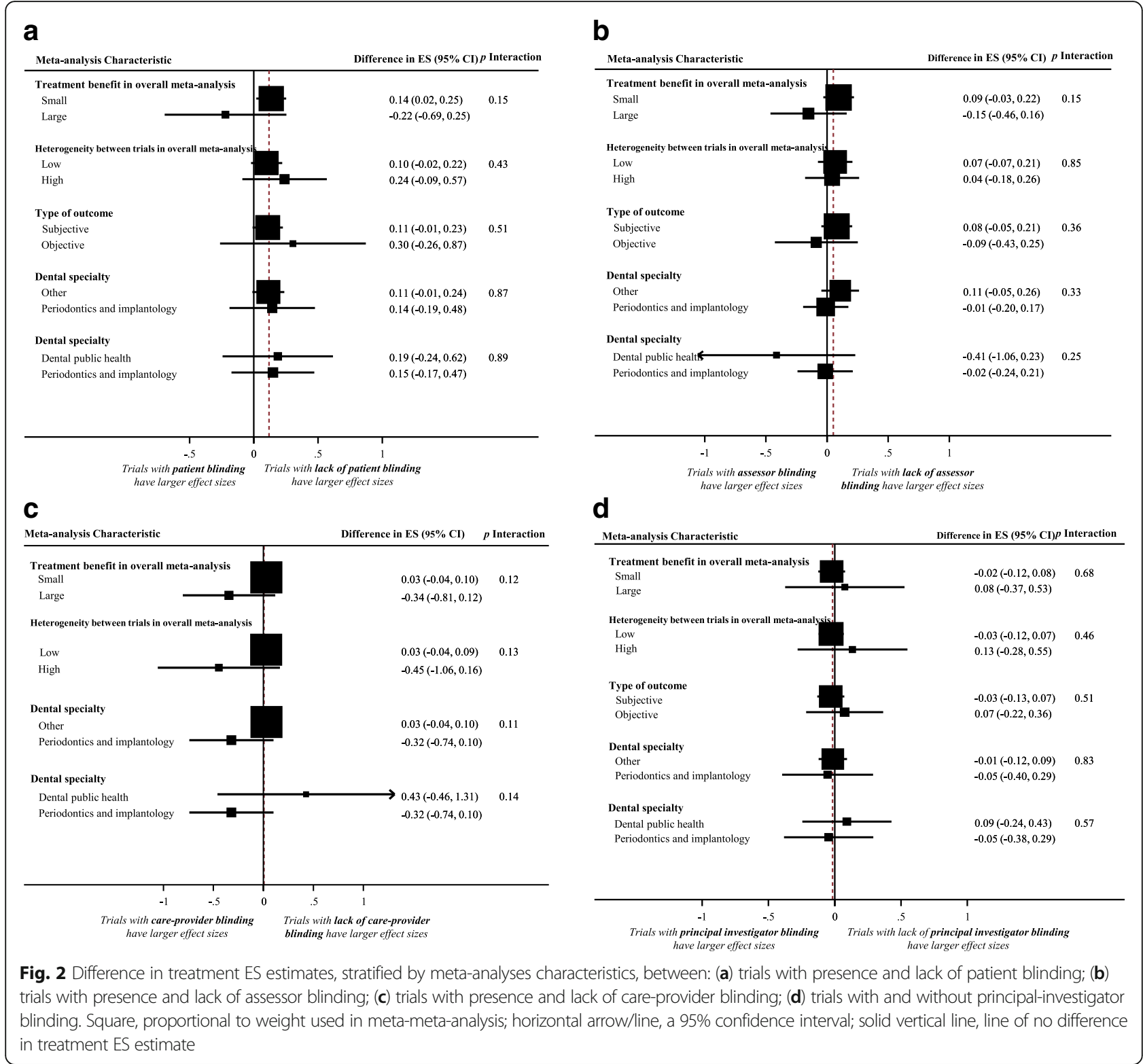

employ blinding of both patients and assessors. However, the impact of blinding of both patients and assessors on treatment ES estimate stratified by examined characteristics of meta-analyses was not statistically significant for any of the characteristics (see Fig. 6b).

\section{Impact of blinding of patients, assessors, and care-} providers concurrently on treatment effect size estimate Figure 7b shows a forest plot of the difference in treatment ES estimate between randomized trials with the presence and lack of blinding of patients, assessors, and care-providers concurrently. Ten meta-analyses, including 151 trials that analyzed 99,293 patients, provided information for this meta-epidemiological analysis. Results of the analysis showed that trials that did not implement patient, assessor, and care-provider blinding had significantly larger treatment ESs (difference $=0.14,95 \%$ confidence interval 0.03 to $0.25, p=0.013$ ) than trials that implemented blinding of those three components. However, results of the stratified analyses show that none of the examined meta-analyses characteristics had a statistically significant interaction with the treatment ES (see Fig. 6c).

\section{Impact of using an appropriate method of blinding on treatment ES}

Figure 8 shows a forest plot of the difference in treatment ES estimates between trials with the presence and lack of an appropriate method of blinding. Forty metaanalyses provided information for this metaepidemiological analysis. Presence of an appropriate 


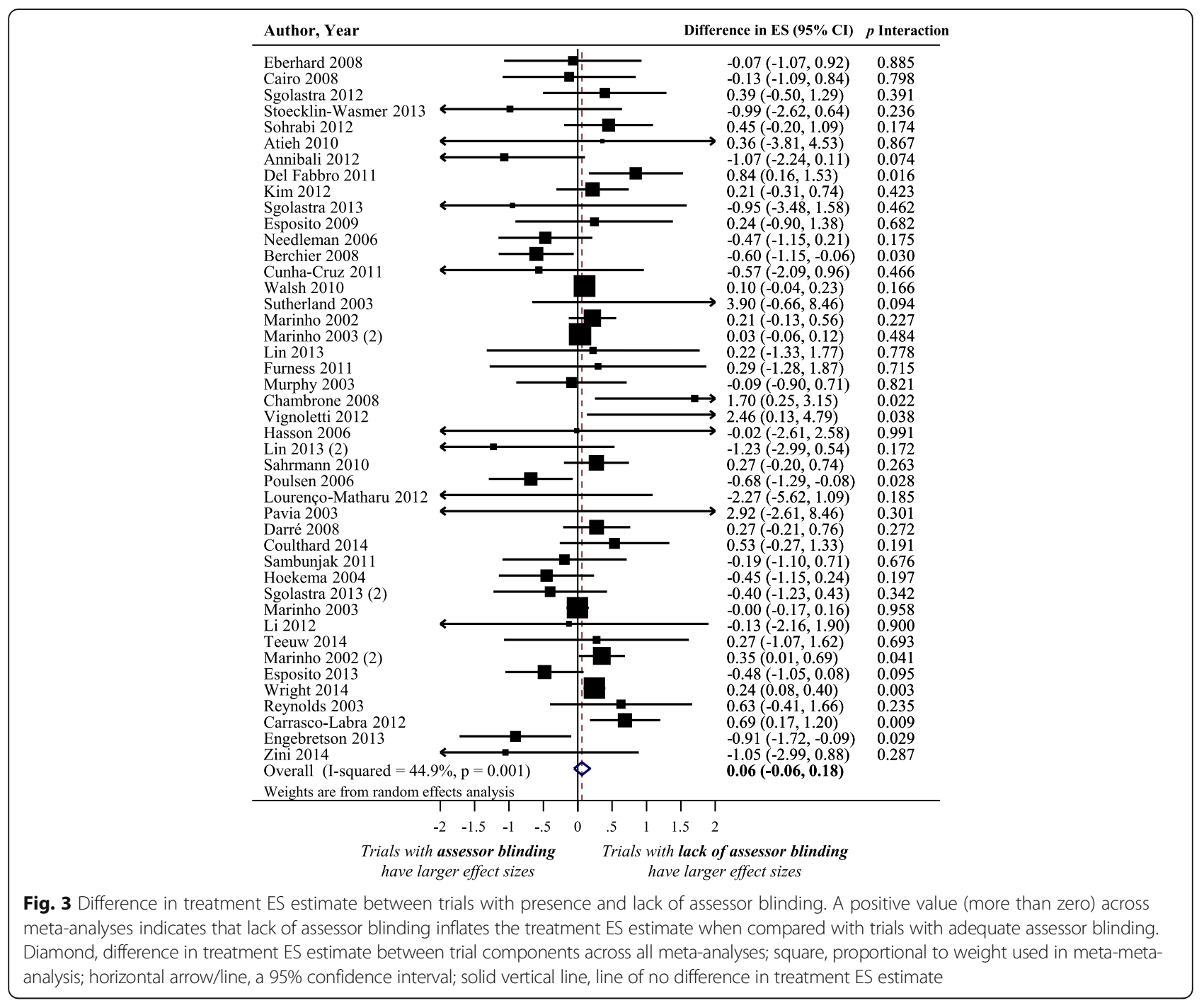

method of blinding was not associated with a statistically significant difference in treatment ES estimate, trials that lacked an appropriate method of blinding tended to inflate treatment ES estimates compared to trials with an appropriate method of blinding (difference $=0.06,95 \%$ confidence interval -0.06 to $0.18, p=0.325$ ). The results of the stratified analyses showed that differences in treatment ES estimates between trials with the presence or lack of appropriate blinding were significant $(p<0.02)$ in meta-analyses with a large treatment benefit in overall meta-analysis, but not in meta-analyses with a small treatment benefit. However, none of the other considered factors (heterogeneity of meta-analysis, type of outcome, and dental specialty) had a statistically significant interaction with the treatment ES estimate (see Fig. 6d).

\section{Discussion}

Our investigation provides empirical evidence of the impact of bias associated with nine blinding-based criteria (related to patient, assessor, care-provider, and principalinvestigator blinding) on the treatment ES estimate. This analysis is important to methodologists and researchers in dental, oral, and craniofacial research. To our knowledge, this study is the first meta-epidemiological study conducted in any medical or dental field that examines continuous outcomes of the impact of blinding of both patients and assessors and of patients, assessors, and care-providers on treatment ES estimates in randomized trials.

Our study shows significant differences in treatment ES estimates in oral health RCTs based on different types of blinding. For example, RCTs with lack of patient and assessor blinding had significantly larger treatment ES estimates compared to trials without lack of patient and/or assessor blinding. Patient blinding and assessor blinding were associated with inflated treatment ES estimates (significant at the level of patient blinding), while care-provider and principal-investigator blinding were 


\section{a}

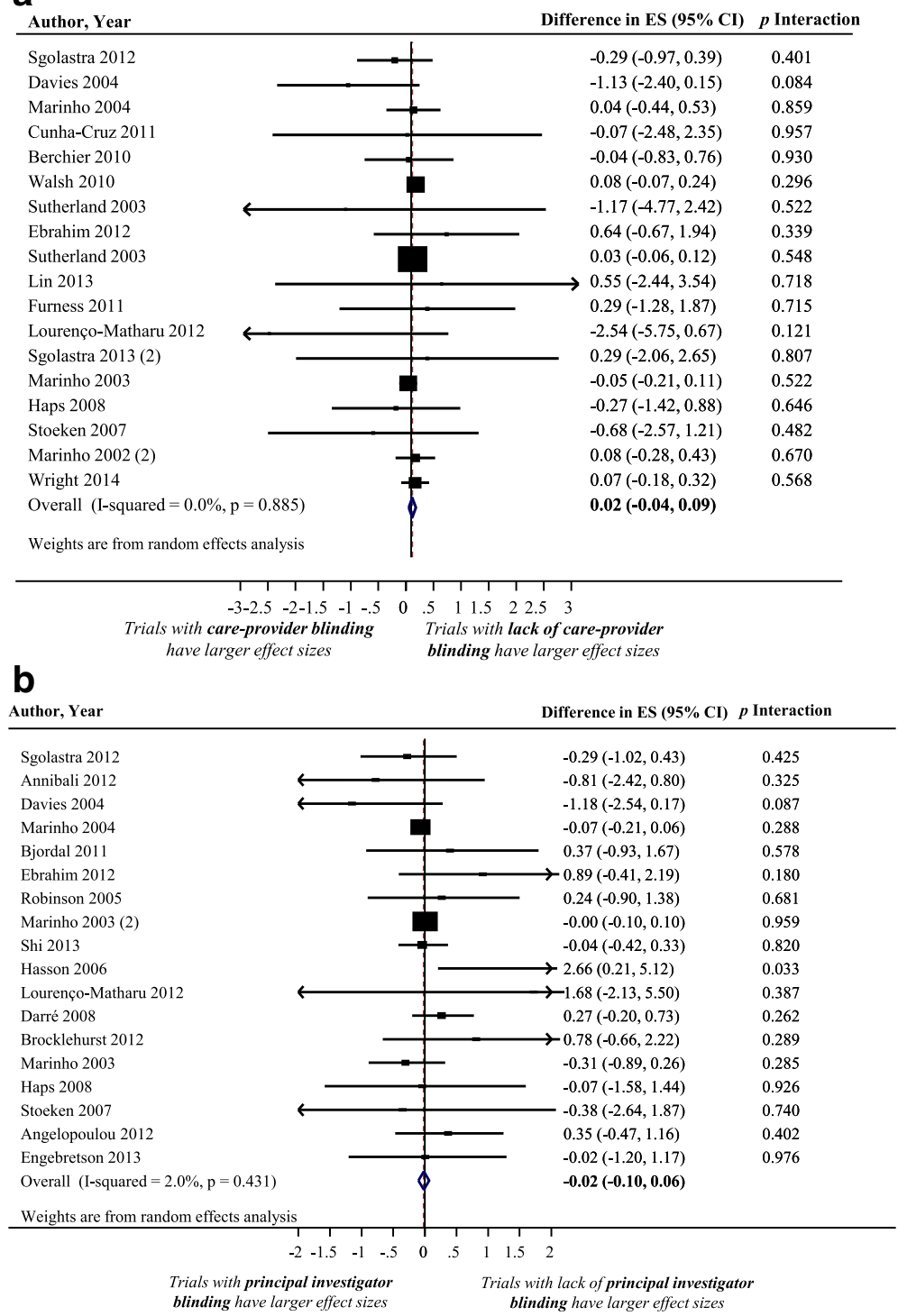

Fig. 4 Difference in treatment ES estimate between: (a) trials with presence and lack of care-provider blinding (a positive value across meta-analyses indicates that the lack of care-provider blinding inflates the treatment ES estimate when compared with trials with adequate care-provider blinding); (b) trials with presence and lack of principal-investigator blinding (a positive value across meta-analyses indicates that the lack of principal-investigator blinding inflates the treatment ES estimate when compared with trials with adequate principal investigator blinding). Diamond, difference in treatment ES estimate between trial components across all meta-analyses; square, proportional to weight used in meta-meta-analysis; horizontal arrow/line, a 95\% confidence interval; solid vertical line, line of no difference in treatment ES estimate

not related to inflated treatment ES estimates. Interestingly, lack of blinding of both assessors and patients was found to be associated with the largest overestimation in treatment ES estimate (0.19). This measured magnitude of bias represents approximately $1 / 3$ of common treatment ES estimates reported in oral health research [50], such as clinical outcomes in periodontology [46]. The fact that treatment ES estimates in oral health trials may have been biased due to lack of blinding is concerning, as clinical decision making related to recommended dental treatments and modalities may therefore not be based on valid findings.

The stratified analyses showed that the extent of bias associated with lack of blinding was not significantly associated with any other factor considered at the metaanalysis level. This agrees with a recent study conducted in the area of physical therapy, and is contrary to other meta-epidemiological studies [51], which showed that trials with subjective outcomes exaggerated treatment ES estimates compared to trials with objective outcomes. 


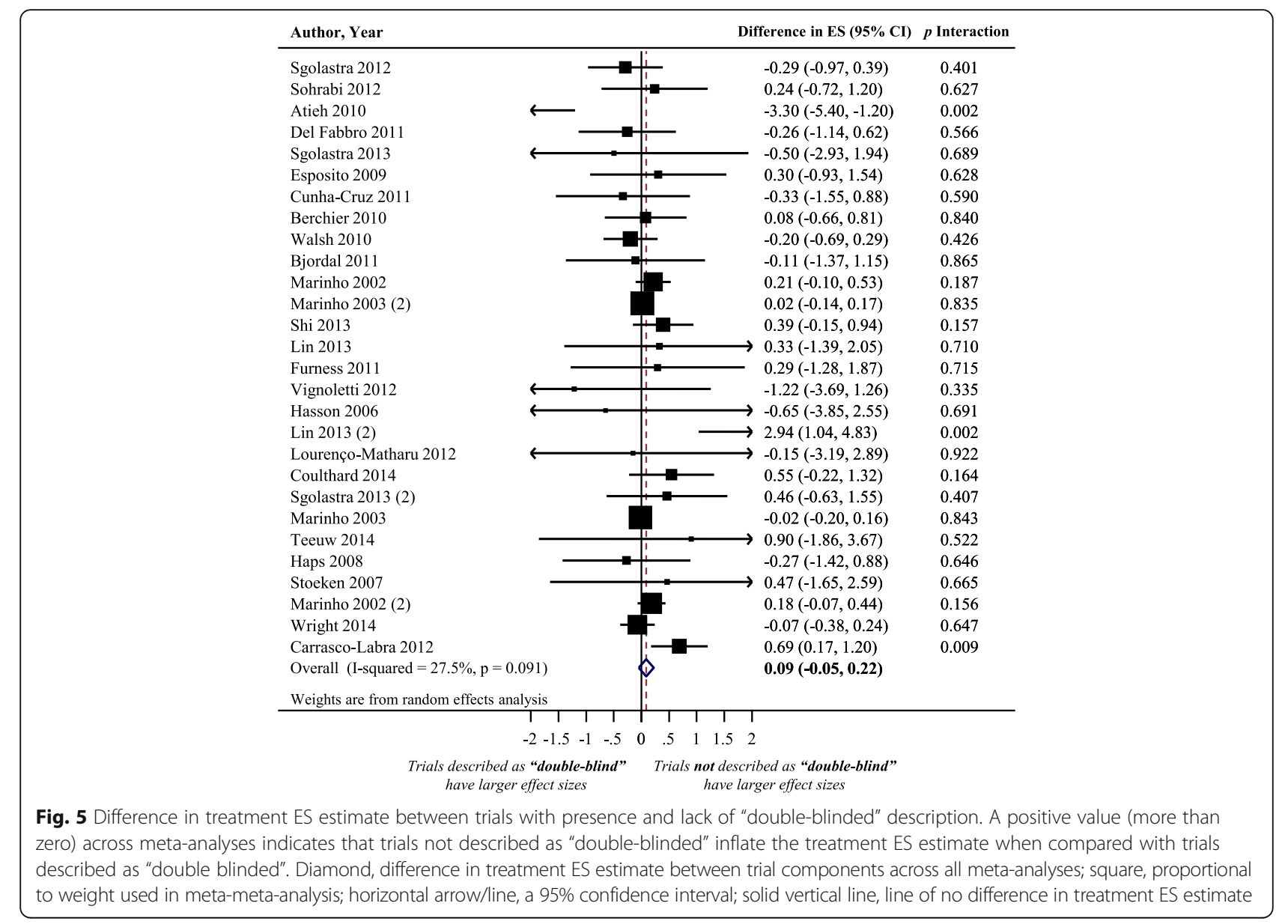

This could be due to having a small number of trials with objective outcomes in our study, or to differences between interventions in different medical disciplines.

Reports examining the impact of lack of blinding of patient, therapist, or assessor on treatment ES estimates were conducted in particular medical fields such as physical therapy [19], thrombosis and cardiovascular disease [15, 21], pediatrics [18], osteoarthritis [45], and low-back pain [16]. The studies reported inconsistent findings. The treatment ES estimate was smaller in trials that employed patient blinding [15] or assessor blinding $[20,21]$ in some studies, whereas in other studies the treatment ES estimate was smaller in trials that lacked patient [17] or assessor blinding [15]. However, an association between the treatment ES estimate and the presence or lack of blinding was not confirmed in some studies $[16,45]$. Furthermore, while the definition of double blinding varied largely among the metaepidemiological studies with respect to the level of blinding (patient, assessor, and care-provider blinding), a lack of double blinding was found to be associated with exaggerated treatment ES estimates in general [22, 23, 52]. The inconsistent findings might be due to the examination of different types of outcome, intervention, and population, to the implementation of different definitions of quality assessment, and to the application of various statistical and modeling approaches [24]. For example, Schulz et al. [52] applied a multiple logistic regression model to analyze data on binary outcomes from 250 trials included in 33 meta-analyses; the definition of double blinding was based on whether the trial's conduct claimed to be double-blinded. Egger et al. [22] defined "double blinding" based on whether the trial was described as double-blind, or included at least assessor blinding; the study analyzed data from 304 trials included in 39 meta-analyses with binary outcomes in several medical fields (infectious diseases, neurology, among others).

Two recent studies $[18,19]$ that examined the association between lack of blinding of patient, therapist, or assessor, and treatment ES using continuous outcomes, also reported inconsistent findings. One study assessed the adequacy of patient and assessor blinding in 287 pediatric trials from 17 meta-analyses [18], and showed no significant difference in treatment ESs between studies, based on potential bias related to lack of blinding. Another study assessed 165 physical therapy trials 




included in 17 meta-analyses and found that trials with a lack of patient or assessor blinding tended to underestimate treatment ES estimate when compared with trials with appropriate blinding (although, the differences were not statistically significant) [19]. It should be noted that in both studies, lack of significant results might be accounted for by the small number of trials, precision of the analyses performed, and/or examination of interventions where blinding is not crucial or fundamental (i.e., outcomes are objective or automated with no assessor involvement).

Because the concept of blinding is implemented at multiple levels of a trial (e.g., patients, assessors, care providers, data analysts, investigators), there is confusion when describing the level of blinding implemented. For example, "double blinding" or "triple blinding" may refer to blinding at any two or three of the previous levels. Failure to clearly report the levels that such terms refer to leads to confusion. Investigators of RCTs conducted in the field of dentistry need to implement and clearly report blinding of patients, assessors, care providers, data analysts, and other personnel when applicable, and explicitly report on mechanisms used to achieve and assure successful blinding, as recommended by the Consolidated Standards of Reporting Trials (CONSORT) statement. In addition, investigators of RCTs should state the levels (e.g., patients, assessors, care providers) and components (e.g. allocation, outcomes assessed, details of interventions) they are referring to when they describe blinding of a trial. In addition, they should avoid using the terms "double" or "triple" blind trial when reporting trial findings, and report who was 


\section{a}



Fig. 7 Difference in treatment ES estimate between: (a) trials with and without blinding of both patients and assessors (a positive value, more than zero, across meta-analyses indicates that lack of blinding of both patients and assessors inflates the treatment ES estimate when compared with trials with adequate blinding of patients and assessors); (b) trials with and without blinding of patients, assessors, and care providers (a positive value, more than zero, across meta-analyses indicates that lack of blinding of patients, assessors, and care providers inflates the treatment ES estimate when compared with trials adequately blinded in the three components). Diamond, difference in treatment ES estimate between trial components across all meta-analyses; square, proportional to weight used in meta-meta-analysis; horizontal arrow/line, a 95\% confidence interval; solid vertical line, line of no difference in treatment ES estimate

blinded and to what components blinding was achieved, so the reader can evaluate potential associated bias. As well, editors and peer reviewers of dental journals should require authors of randomized trials to adhere to the CONSORT guidelines and insist on adequate conduct and reporting of blinding in submitted randomized trials.

When we examined the association between double blinding and treatment ES, we performed the analysis on two different criteria: reporting of "double blinding" as a term in a trial, and actual conduct of blinding of both assessors and patients. Haahr and Hróbjartsson [53], who examined a random sample of RCTs from the Cochrane Central Register of Controlled Trials, suggested that it is incorrect to assume blinding of a trial participant based only on the term "double blind." The study found that blinding of patients, care providers, and assessors was clearly described in only three $(2 \%)$ of 200 blinded RCTs, while $56 \%$ of trials failed to describe blinding status of any individual involved in a trial. That study concluded that either patients, care providers, or assessors were not blinded in one of five "double blind" RCTs. Another trial study [54] showed that adequate reporting of blinding was common in some medical journals, and that inadequate reporting of blinding does not necessarily entail a lack of actual blinding. For example, it was reported that RCT authors frequently use blinding, although they fail to describe its methods. For instance, authors of RCTs failed to report the blinding 


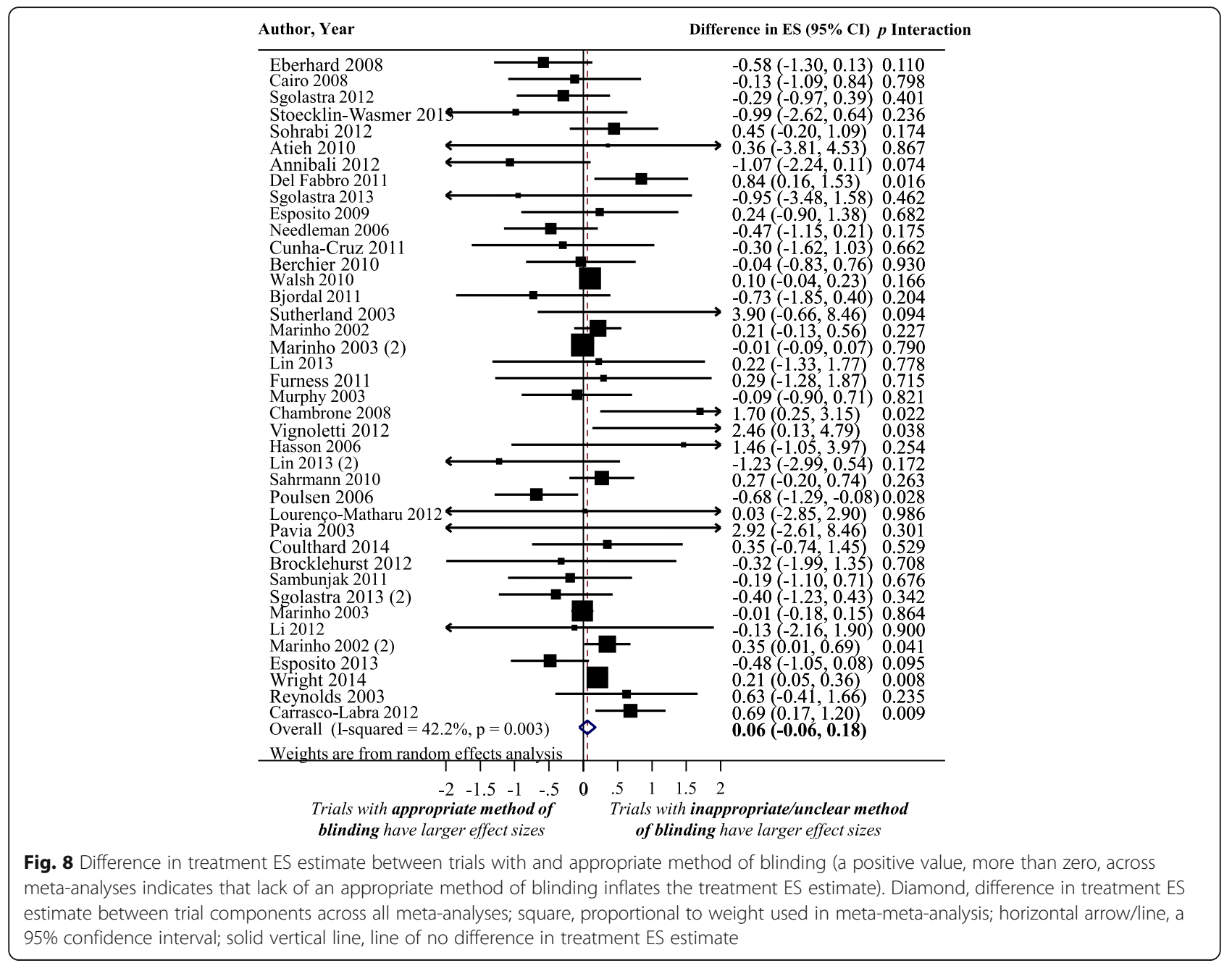

status of patients in $26 \%$ of trials, and patients were actually blinded in $20 \%$ of trials in which patients were not reported to be blinded. Similar results were found in a recent study by Kahan et al. [55], who reported that blinding of outcome assessors is uncommonly used and inadequately reported in a cohort of 258 trials published in four high-impact medical journals.

An implication that can be drawn from our metaepidemiological work is that authors of systematic reviews of oral health interventions should consider excluding dental RCTs with lack of blinding from metaanalyses, or at least perform sensitivity analyses on included trials based on the adequacy of blinding. In all instances, authors should consider the likely level of bias associated with reported (or unreported) blinding status when interpreting the findings of a quantitative analysis.

The above-mentioned implications should be considered with caution, particularly in oral health trials involving surgical or device interventions (such as orthodontic trials) where patient blinding is not feasible; in this case, informing patients with details of the intervention is required, and sometimes ethically compulsory. While these RCTs are prone to biases, particularly when the RCTs examine self-reported outcomes, implementation of blinding in the conduct of these trials is often unacceptable for ethical and practical reasons. For example, in the case of trials comparing surgical interventions to nonsurgical interventions (e.g., comparison of surgical removal of wisdom teeth versus retention or conservative management), patients and surgeons cannot be blinded. However, trialists may consider using "expertise-based" trial design, whereby patients are allocated to multiple surgeons and each surgeon performs a single treatment [56]. While this design helps to minimize performance bias related to surgeon blinding, it does not ensure patient blinding [57]. Furthermore, in trials where patients cannot be blinded (e.g., comparison of manual versus electric toothbrushing), trialists may consider using objective outcomes that have established validity and reliability [56] or blind patients to trial's hypothesis. When blinding is feasible, trialists should consider blinding as many trial components 
(participants, assessors, care-providers, statisticians, investigators) as ethically and practically possible.

Based on this evidence, investigators of systematic reviews conducted in dental, oral, and craniofacial trials should perform sensitivity analyses based on the adequacy of blinding in included trials. The potential impact of blinding on bias in treatment ES suggests that dental journal editors and reviewers should insist on adequate blinding (when feasible) with respect to trial conduct and reporting, in published trials' reports.

\section{Strengths and limitations of the study}

This meta-epidemiological study provides an empirical analysis of the association between treatment ES estimates and bias, in the domain of oral health research. The study has several limitations.

First, we examined published studies only (bias was based on reported methodological characteristics), and did not evaluate actual conduct of the RCTs. Accordingly, data extraction and analyses were based on information given by authors in published reports. This approach, although widely used, limits the identification of actual bias if trial authors do not adequately report study elements.

Second, while there are many ways for an RCT planned as blinded to become unblinded, [58] our study did not use specific mechanisms to look for evidence of unblinding, such as differential (across treatment groups) incidences of specific adverse events that would give away which patients received which interventions and large baseline imbalances indicative of the type of selection bias that may occur with unsuccessful allocation concealment $[59,60]$. Also, our study did not look at how many RCTs reported a valid and reliable method of assessment of the success of blinding such as the Berger-Exner test of selection bias [58]. Accordingly, future RCTs should routinely conduct and report the results of a valid and reliable method of assessing the success of blinding (such as the Berger-Exner test) based on the extent to which any unblinding led to selection bias $[61,62]$.

Third, certain levels of heterogeneity are expected in any meta-epidemiological examination of the impact of bias on treatment ES estimates. Such studies analyse numerous entities (meta-analysis, trials, and participants) that have a distinct potential for heterogeneity [24]. By applying a cautious methodology to data collection and analysis in this study, and by assembling a large number of meta-analyses and trials, study power was increased and heterogeneity was reduced.

Fourth, because our study did not compare the same treatment with different degrees of blinding, the identified evidence could lead to the conclusion that trials of interventions where blinding is not feasible, such as surgery or devices, have in general higher treatment ES estimates. Future meta-epidemiological studies should further investigate the above-mentioned concept.

Finally, this study did not assess the likely effects of interactions with other design biases. Such an assessment would have to include a multivariate analysis with a larger number of meta-analyses and trials [17]. Future meta-epidemiological assembling of a greater number of meta-analyses and trials by synthesizing results from different disciplines and datasets should take other design biases into account.

\section{Conclusions}

We found significant differences in treatment ESs between oral health RCTs based on lack of patient and assessor blinding. RCTs that lacked patient and assessor blinding had significantly larger treatment ES estimates. Treatment ES estimates were 0.19 and 0.14 larger in trials with lack of blinding of both patients and assessors and blinding of patients, assessors, and care-providers concurrently. No significant differences were identified in other blinding criteria. Future meta-epidemiological assembling of a greater number of meta-analyses and trials that takes other biases and different degrees of blinding into account is needed.

\section{Additional files}

Additional file 1: Appendix 2. This file contains search strategy used in the study. (DOCX 44 kb)

Additional file 2: Appendix 1. This file contains details of the metaanalyses included in the study. (DOCX $131 \mathrm{~kb}$ )

\section{Abbreviations}

ES: Effect size; RCT: Randomized controlled trial

\section{Acknowledgments}

HS is supported through a Clinician Fellowship Award by Alberta Innovates Health Solutions (AlHS), the Honorary Izaak Walton Killam Memorial Scholarship by the University of Alberta, Alpha Omega Foundation of Canada Grant, and the Honorary WCHRI Award by the Women and Children's Health Research Institute (WCHRI). SAO is supported by the Canadian Institutes of Health Research (CIHR) through a full-time Banting fellowship, the Alberta Innovates Health solution through an incentive award, the STIHR Training Program from Knowledge Translation (KT) Canada, and a "Music in Motion" Fellowship from the Faculty of rehabilitation Medicine. GGC held a Population Health Investigator award from the Alberta Heritage Foundation for Medical Research (2006 to 2013), and now holds a Centennial Professorship at the University of Alberta (2013 to 2020).

Informed consent

For this type of study, formal consent is not required.

\section{Funding}

This study was supported through a Clinician Fellowship Award by Alberta Innovates - Health Solutions (AlHS). The funders had no role in study design, decision to publish, or preparation of the manuscript. 


\section{Availability of data and materials}

The datasets used and/or analysed during the current study are available from the corresponding author on reasonable request.

\section{Authors' contributions}

$\mathrm{HS}, \mathrm{SA}-\mathrm{O}, \mathrm{BdC}$ collected and analyzed the data; HS drafted the manuscript and integrated critical feedback from the other authors. HS, SA-O, GC, MA, $\mathrm{BdC}, \mathrm{CF}$, were involved in interpretation of the data. $\mathrm{HS}, \mathrm{SA}-\mathrm{O}, \mathrm{GC}, \mathrm{MA}, \mathrm{BdC}$, CF provided feedback on the revisions to the manuscript. All authors read and approved the final manuscript.

\section{Ethics approval and consent to participate}

This article does not contain any studies with human participants or animals performed by any of the authors.

\section{Competing interests}

The authors declare that they have no competing interests.

\section{Publisher's Note}

Springer Nature remains neutral with regard to jurisdictional claims in published maps and institutional affiliations.

\section{Author details}

'Orthodontic Graduate Program, School of Dentistry, Edmonton Clinic Health Academy, University of Alberta, 11405-87 Ave, Edmonton, AB T6G 1C9, Canada. ${ }^{2}$ Faculty of Rehabilitation Medicine, University of Alberta, Edmonton, AB, Canada. ${ }^{3}$ Faculty of Nursing, University of Alberta, Edmonton, AB, Canada. ${ }^{4}$ Division of Pediatric Dentistry, School of Dentistry, University of Alberta, Edmonton, $A B$, Canada. ${ }^{5}$ Department of Physical Therapy, Institute of Primary Health Care (BIHAM), Florida International University, Miami, USA. ${ }^{6}$ University of Bern, Bern, Switzerland. 'Division of Orthodontics, School of Dentistry, University of Alberta, Edmonton, Canada.

\section{Received: 7 June 2017 Accepted: 15 April 2018}

\section{Published online: 18 May 2018}

\section{References}

1. Needleman I, Moher D, Altman DG, Schulz KF, Moles DR, Worthington H. Improving the clarity and transparency of reporting health research: a shared obligation and responsibility. J Dent Res. 2008:87(10):894-5.

2. Needleman I, Worthington H, Moher D, Schulz K, Altman DG. Improving the completeness and transparency of reports of randomized trials in oral health: the CONSORT statement. Am J Dent. 2008;21(1):7-12.

3. Saltaji H, Cummings GG, Armijo-Olivo S, Major MP, Amin M, Major PW, Hartling L, Flores-Mir C. A descriptive analysis of oral health systematic reviews published 1991-2012: cross sectional study. PLoS One. 2013;8(9):e74545.

4. Moher D, Cook DJ, Jadad AR, Tugwell P, Moher M, Jones A, Pham B, Klassen TP. Assessing the quality of reports of randomised trials: implications for the conduct of meta-analyses. Health Technol Assess. 1999;3(12):i-iv):1-98.

5. Moher D, Schulz KF, Altman DG. The CONSORT statement: revised recommendations for improving the quality of reports of parallel-group randomized trials. J Am Podiatr Med Assoc. 2001;91(8):437-42.

6. Moher D, Hopewell S, Schulz KF, Montori V, Gotzsche PC, Devereaux PJ, Elbourne D, Egger M, Altman DG. CONSORT 2010 explanation and elaboration: updated guidelines for reporting parallel group randomised trials. Int J Surg. 2012;10(1):28-55.

7. Armijo-Olivo S, Fuentes J, Ospina M, Saltaji H, Hartling L. Inconsistency in the items included in tools used in general health research and physical therapy to evaluate the methodological quality of randomized controlled trials: a descriptive analysis. BMC Med Res Methodol. 2013;13:116.

8. Delgado-Rodriguez M, Llorca J. Bias. J Epidemiol Community Health. 2004; 58(8):635-41.

9. Gluud LL. Bias in clinical intervention research. Am J Epidemiol. 2006; 163(6):493-501.

10. Pandis N. Blinding or masking. Am J Orthod Dentofac Orthop. 2012; 141(3):389-90.

11. Schulz KF, Grimes DA. Blinding in randomised trials: hiding who got what. Lancet. 2002;359(9307):696-700.

12. Boutron I, Moher D, Altman DG, Schulz KF, Ravaud P. Extending the CONSORT statement to randomized trials of nonpharmacologic treatment explanation and elaboration. Ann Intern Med. 2008;148(4):295-309.
13. McCulloch P, Taylor I, Sasako M, Lovett B, Griffin D. Randomised trials in surgery: problems and possible solutions. BMJ. 2002;324(7351):1448-51.

14. Nuesch E, Reichenbach S, Trelle S, Rutjes AW, Liewald K, Sterchi R, Altman $D G$, Juni P. The importance of allocation concealment and patient blinding in osteoarthritis trials: a meta-epidemiologic study. Arthritis Rheum. 2009; 61(12):1633-41.

15. Balk EM, Bonis PA, Moskowitz H, Schmid CH, loannidis JP, Wang C, Lau J. Correlation of quality measures with estimates of treatment effect in metaanalyses of randomized controlled trials. JAMA. 2002;287(22):2973-82.

16. van Tulder MW, Suttorp M, Morton S, Bouter LM, Shekelle P. Empirical evidence of an association between internal validity and effect size in randomized controlled trials of low-back pain. Spine. 2009;34(16):1685-92.

17. Hempel S, Miles J, Suttorp MJ, Wang Z, Johnsen B, Morton S, Perry T, Valentine D, Shekelle PG. Detection of Associations Between Trial Quality and Effect Sizes. Rockville (MD): Agency for Healthcare Research and Quality (US); 2012.

18. Hartling L, Hamm MP, Fernandes RM, Dryden DM, Vandermeer B. Quantifying bias in randomized controlled trials in child health: a metaepidemiological study. PLoS One. 2014;9(2):e88008.

19. Armijo-Olivo S, Fuentes J, da Costa BR, Saltaji H, Ha C, Cummings GG. Blinding in physical therapy trials and its association with treatment effects: a meta-epidemiological study. Am J Phys Med Rehabil. 2017;96(1):34-44.

20. Hrobjartsson A, Thomsen AS, Emanuelsson F, Tendal B, Hilden J, Boutron I, Ravaud $\mathrm{P}$, Brorson S. Observer bias in randomised clinical trials with binary outcomes: systematic review of trials with both blinded and non-blinded outcome assessors. BMJ. 2012;344:e1119.

21. Juni $P$, Witschi A, Bloch R, Egger M. The hazards of scoring the quality of clinical trials for meta-analysis. JAMA. 1999;282(11):1054-60.

22. Egger M, Juni $P$, Bartlett $C$, Holenstein F, Sterne J. How important are comprehensive literature searches and the assessment of trial quality in systematic reviews? Empirical study Health Technol Assess. 2003;7(1):1-76.

23. Wood L, Egger M, Gluud LL, Schulz KF, Juni P, Altman DG, Gluud C, Martin RM, Wood AJ, Sterne JA. Empirical evidence of bias in treatment effect estimates in controlled trials with different interventions and outcomes: meta-epidemiological study. BMJ. 2008;336(7644):601-5.

24. Berkman ND, Santaguida PL, Viswanathan M, Morton SC. The Empirical Evidence of Bias in Trials Measuring Treatment Differences. Rockville (MD): Agency for Healthcare Research and Quality (US); 2014.

25. Saltaji H, Armijo-Olivo S, Cummings GG, Amin M, Flores-Mir C. Methodological characteristics and treatment effect sizes in oral health randomised controlled trials: is there a relationship? Protocol for a metaepidemiological study. BMJ Open. 2014;4(2):e004527.

26. ADA. Specialty Definitions. Available at: http://www.ada.org/495.aspx. Accessed July 2015.

27. Piromchai P, Thanaviratananich S, Laopaiboon M. Systemic antibiotics for chronic rhinosinusitis without nasal polyps in adults. Cochrane Database Syst Rev. 2011;5:CD008233.

28. Trees AH, Howe TE, Grant M, Gray HG. Exercise for treating anterior cruciate ligament injuries in combination with collateral ligament and meniscal damage of the knee in adults. Cochrane Database Syst Rev. 2011;5:CD005961.

29. Armijo-Olivo S, Ospina M, da Costa BR, Egger M, Saltaji H, Fuentes CJ, Ha C, Cummings GG. Poor reliability between Cochrane reviewers and blinded external reviewers when applying the Cochrane risk of Bias tool in physical therapy trials. PLoS One. 2014;9(5):e96920.

30. Armijo-Olivo S, Saltaji H, da Costa BR, Fuentes J, Ha C, Cummings GG. What is the influence of randomisation sequence generation and allocation concealment on treatment effects of physical therapy trials? A metaepidemiological study. BMJ Open. 2015;5(9):e008562.

31. Jadad AR, Moore RA, Carroll D, Jenkinson C, Reynolds DJ, Gavaghan DJ, McQuay HJ. Assessing the quality of reports of randomized clinical trials: is blinding necessary? Contr Clin Trials. 1996;17(1):1-12.

32. Verhagen AP, de Vet $H C$, de Bie RA, Kessels AG, Boers $M$, Bouter $L M$, Knipschild PG. The Delphi list: a criteria list for quality assessment of randomized clinical trials for conducting systematic reviews developed by Delphi consensus. J Clin Epidemiol. 1998;51(12):1235-41.

33. van Tulder M, Furlan A, Bombardier C, Bouter L. Updated method guidelines for systematic reviews in the cochrane collaboration back review group. Spine. 2003;28(12):1290-9.

34. van Tulder MW, Assendelft WJ, Koes BW, Bouter LM. Method guidelines for systematic reviews in the Cochrane collaboration back review Group for Spinal Disorders. Spine. 1997;22(20):2323-30. 
35. Moseley AM, Herbert RD, Sherrington C, Maher CG. Evidence for physiotherapy practice: a survey of the physiotherapy evidence database (PEDro). Aust. J. Physiother. 2002;48(1):43-9.

36. Sherrington C, Herbert RD, Maher CG, Moseley AM. PEDro. A database of randomized trials and systematic reviews in physiotherapy. Man Ther. 2000;5(4):223-6.

37. Bizzini M, Childs JD, Piva SR, Delitto A. Systematic review of the quality of randomized controlled trials for patellofemoral pain syndrome. J Orthop Sports Phys Ther. 2003;33(1):4-20.

38. Armijo-Olivo S, Macedo LG, Gadotti IC, Fuentes J, Stanton T, Magee DJ. Scales to assess the quality of randomized controlled trials: a systematic review. Phys Ther. 2008;88(2):156-75.

39. Higgins JP1, Altman DG, Gøtzsche PC, Jüni $P$, Moher D, Oxman AD, Savovic J, Schulz KF, Weeks L, Sterne JA, Cochrane Bias Methods Group, Cochrane Statistical Methods Group. The Cochrane Collaboration's tool for assessing risk of bias in randomised trials. BMJ. 2011;343:d5928.

40. Sterne JA, Juni P, Schulz KF, Altman DG, Bartlett C, Egger M. Statistical methods for assessing the influence of study characteristics on treatment effects in 'meta-epidemiological' research. Stat Med. 2002; 21(11):1513-24.

41. DerSimonian R, Kacker R. Random-effects model for meta-analysis of clinical trials: an update. Contemp Clin Trials. 2007;28(2):105-14.

42. Higgins JP, Green S, editors. Cochrane handbook for systematic reviews of interventions version 5.0.0. Oxford (UK): Cochrane Collaboration; 2008.

43. Cohen J. Chapter 1: The Concepts of Power Analysis. In: Statistical Power Analysis for the Behavioral Sciences. Second edn. Edited by Cohen J. Hillsdale, New jersey: Academic Press, INc; 1988. 1-17.

44. Hempel S, Miles JN, Booth MJ, Wang Z, Morton SC, Shekelle PG. Risk of bias: a simulation study of power to detect study-level moderator effects in meta-analysis. Syst Rev. 2013;28;2:107.

45. Nuesch E, Reichenbach S, Trelle S, AWS R, Liewald K, Sterchi R, Altman DG, Juni $P$. The importance of allocation concealment and patient blinding in osteoarthritis trials: A meta-epidemiologic study. Arthritis Care Res. 2009; 61(12):1633-41.

46. Fenwick J, Needleman IG, Moles DR. The effect of bias on the magnitude of clinical outcomes in periodontology: a pilot study. J Clin Periodontol. 2008; 35(9):775-82.

47. Saltaji H. Historical controls in orthodontics: need for larger metaepidemiological studies. Eur J Orthod. 2017;39(1):106.

48. Saltaji H, Armijo-Olivo S, Cummings GG, Amin M, da Costa BR, Flores-Mir C. Impact of selection Bias on treatment effect size estimates in randomized trials of oral health interventions: a meta-epidemiological study. J Dent Res. 2018;97(1):5-13

49. Saltaji H, Armijo-Olivo S, Cummings GG, Amin M, Flores-Mir C. Randomized clinical trials in dentistry: Risks of bias, risks of random errors, reporting quality, and methodologic quality over the years 1955-2013. PloS one. 2017;12(12): e0190089.

50. Pandis N. The effect size. Am J Orthod Dentofac Orthop. 2012;142(5):739-40.

51. Hróbjartsson A, Emanuelsson F, Skou Thomsen AS, Hilden J, Brorson S. Bias due to lack of patient blinding in clinical trials. A systematic review of trials randomizing patients to blind and nonblind sub-studies. Int J Epidemiol. 2014;43(4):1272-83.

52. Schulz KF, Chalmers I, Hayes RJ, Altman DG. Empirical evidence of bias. Dimensions of methodological quality associated with estimates of treatment effects in controlled trials. JAMA. 1995;273(5):408-12.

53. Haahr MT, Hrobjartsson A. Who is blinded in randomized clinical trials? A study of 200 trials and a survey of authors. Clin Trials. 2006;3(4):360-5.

54. Devereaux PJ, Choi PTL, El-Dika S, Bhandari M, Montori VM, Schünemann HJ, Garg AX, Busse JW, Heels-Ansdell D, Ghali WA, et al. An observational study found that authors of randomized controlled trials frequently use concealment of randomization and blinding, despite the failure to report these methods. J Clin Epidemiol. 2004;57(12):1232-6.

55. Kahan BC, Rehal S, Cro S. Blinded outcome assessment was infrequently used and poorly reported in open trials. PLoS One. 2015;10(6):e0131926.

56. Karanicolas PJ, Farrokhyar F, Bhandari M. Practical tips for surgical research: blinding: who, what, when, why, how? Can J Surg. 2010;53(5):345-8.

57. Devereaux PJ, Bhandari M, Clarke M, Montori VM, Cook DJ, Yusuf S, Sackett DL, Cina CS, Walter SD, Haynes B, et al. Need for expertise based randomised controlled trials. BMJ. 2005;330(7482):88.

58. Berger W. On the insufficiency of reporting masking. J Rehabil Med. 2013; 45(2):221-2
59. Berger W. Conservative handling of missing information. J Clin Epidemiol. 2012;65(11):1237-8.

60. Berger W. Internal validity and the risk of bias: a case for a comprehensive review. J Anesth. 2012;26(5):802-3.

61. Berger W. Response to letter by Berger: the success of masking should be tested routinely and correctly. J Clin Epidemiol. 2016;69:265-6.

62. Berger $W$. Quantifying the magnitude of baseline covariate imbalances resulting from selection bias in randomized clinical trials. Biom J. 2005 Apr;47(2):119-27.

63. De Vet HCW, De Bie RA, Van Der Heijden GJMG, Verhagen AP, Sijpkes P, Knipschild PG. Systematic reviews on the basis of methodological criteria. Physiotherapy. 1997;83(6):284-9.

\section{Ready to submit your research? Choose BMC and benefit from:}

- fast, convenient online submission

- thorough peer review by experienced researchers in your field

- rapid publication on acceptance

- support for research data, including large and complex data types

- gold Open Access which fosters wider collaboration and increased citations

- maximum visibility for your research: over $100 \mathrm{M}$ website views per year

At BMC, research is always in progress.

Learn more biomedcentral.com/submissions 